Daria Pašalić*, Evgenija Homšak, Antonio Buño, Katarzyna Bergmann and Ciriaco Carru, on behalf of the European Federation of Clinical Chemistry and Laboratory Medicine (EFLM), Committee on Education and Training (C-ET), Working Group for Congresses and Postgraduate Education (WG-CPE)

\title{
Practice in financial support of third party organised conferences and courses at a national level for health care professionals in Europe
}

https://doi.org/10.1515/cclm-2019-0181

Received February 14, 2019; accepted March 12, 2019; previously published online April 16, 2019

\section{Abstract}

Background: Ethical MedTech prescribes high standards for the participation of the in vitro diagnostics (IVD) industry in third-party organised educational events in terms of charitable donations, educational grants, scholarships and fellowships. We planned a survey to investigate the previous and current practice in terms of cooperation between professionals or professional societies and the IVD industry, as well as plans under the incorporation of the MedTech Europe Code.

Methods: Different questions, from general information to specific questions related to the practice and knowledge of the new Ethical MedTech Code, were included in two different surveys; for European Federation of Clinical Chemistry and Laboratory Medicine (EFLM) National Societies' (NSs) representatives, and for their (NSs) individual members.

Results: Twenty-five out of 40 EFLM NS representatives replied; more than half declared that all different types of financial resources were available for supporting the continuing professional education of health care professionals (HCPs). In addition, 322 individual responses collected from 31 NSs, answered that the institutional director

\footnotetext{
*Corresponding author: Daria Pašalić, Department of Medical Chemistry, Biochemistry and Clinical Chemistry, School of Medicine, University of Zagreb, Zagreb, Croatia, E-mail: daria.pasalic@mef.hr. https://orcid.org/0000-0002-5741-6168

Evgenija Homšak: Department of Laboratory Diagnostics, University Clinical Centre Maribor, Maribor, Slovenia

Antonio Buño: Department of Laboratory Medicine, Hospital University La Paz, Madrid, Spain

Katarzyna Bergmann: Department of Laboratory Medicine, Nicolaus Copernicus University, Collegium Medicum, Bydgoszcz, Poland Ciriaco Carru: Department of Biomedical Sciences, University of Sassari, Sassari, Italy
}

(50.3\%) or laboratory chief $(70.1 \%)$ made generally made a decision, without specific criteria.

Conclusions: The MedTech Europe Code is already adopted or is about to be adopted in numerous EFLM NSs, but most of them have not implemented it as yet. The use of the Code and better communication between IVD companies and HCPs are necessary to guarantee an improved and fair use of financial support, as well as better choices for the organisation and attendance at scientific events.

Keywords: educational events; EFLM Survey; financial support; IVD industry; MedTech; National Societies.

\footnotetext{
The MedTech Europe Code is already adopted or is about to be adopted in numerous EFLM NSs, but most of them have not implemented it as yet.

- The use of the Code and better communication between IVD representatives and HCPs are necessary to guarantee an improved and fair use of financial support.

- It was shown that we still need more education and awareness to increase understanding and practical application of the Code especially among individual HCPs but also among EFLM NSs.
}

\section{Introduction}

Technology plays a crucial role in modern laboratory medicine, and continuous technological innovation is necessary to improve performances in terms of quality, time expenditure and costs [1]. It creates the necessity of constant learning and training by laboratory healthcare professionals (HCPs) about the technological improvements proposed by the modern industry. On the other hand, the in vitro diagnostics (IVD) industry needs to promote and finally to sell its own products. This led to a bidirectional interaction, which needs to be regulated, in order to avoid conflicts of interest and ethical concerns. 
In order to create an ethical interaction between HCPs and industry, MedTech was recently organised in Europe including the countries of the European Economic Area (EEA) and the countries in which the associated national associations are located [2]. MedTech is a trade association representing the medical technology industry, including the IVD industry, that promotes a balanced policy environment enabling the medical technology industry to meet the growing healthcare needs and expectations of its stakeholders, and recognises that compliance with applicable laws and regulations as well as adherence to ethical standards are both essential for the achievement of these goals [2]. Other associations with similar purposes have been recently created in the world [3].

MedTech Code Europe recently defined a Code of Ethical Business Practice in the interaction between industry and HCPs [4]. The Code was created by Eucomed's (Medical Devices) and EDMA's (IVD) members in December 2015 and became effective on January 2017. The section describing the very serious and strong ethical standards in the sponsorship of conferences became effective in January 2018. Nowadays, all laboratory medicine NSs should be aware of the composition and the importance of the topics defined in the MedTech Code. To date, it is not well known how and to what degree NSs were able to incorporate the MedTech requirements and educate their members to organise or participate in educational events which could be financially supported by the IVD industry.

Educational events organised by the European Federation of Clinical Chemistry and Laboratory Medicine (EFLM) and its NSs or so-called "third-party-organised educational events" are a major subject in the MedTech Code. The Code prescribes high standards for the participation of the IVD industry in third-party-organised events in terms of charitable donations, educational grants, scholarships and fellowships [4]. The IVD-industry (EDMA and EUCOMED member companies) can support programmes but only in accordance with written grant agreements which strictly prescribe that the selection of participants, the determination of the educational programme and the locations of the event has to be the responsibility of the organiser [3, 4]. In sum, the IVD-industry cannot directly support individual HCP participants or lecturers; this is also encouraged by other codes of conduct, but it is not yet completely banned [5]. Whenever possible, the organiser must comply with the general criteria for the events that are prescribed in the congress vetting system [6]. The responsibility of organiser is also to provide an equitable selection of participants.
The EFLM and its NSs have many years of experience in organising educational events like congresses, conferences, courses and workshops. The organisation of such meetings is always a major challenge to support the education and training activities of the HCPs who, however, also need significant financial support. The IVD industry has a significant impact on both the development of the profession and the financial support of such meetings.

It is well known that there are different practices with regard to meeting financial support among NSs, and also within each NS, particularly with respect to individual sponsorship participation of HPCs in a variety of educational events.

Some EFLM NSs' individual members can have the opportunity to use institutional budgets which are provided for each HCP or can use a university's financial support for academic professionals (APs), or they can avail of the financial budgets from national and international scientific projects, educational grants provided by NSs, private finances and also funds provided by the IVD industry.

With the aim to investigate data about previous and current practice in cooperation between professionals, scientific societies and the IVD-industry, the EFLM Working Group: Congresses and Postgraduate Education (WG-CPE) conducted a survey involving the EFLM NSs (presidents or national representatives) and individual NS members (HCPs and APs).

The aim of the survey was to investigate the previous and current practice in terms of cooperation between professionals or professional societies and the IVD industry, as well as future plans for the incorporation of the MedTech Europe Code among NSs that are members of the EFLM.

\section{Materials and methods}

\section{Subjects and surveys}

Two different surveys were created by the members of the EFLM WG-CPE, which work within the Education and Training Committee (C-ET). The first survey was created for NSs and addressed to NS representatives (NSR). The other survey was created for all individual members (IM) of different NSs.

Both surveys were composed of a first part that aimed to collect general information and a further part with specific questions related to the practice and knowledge of the MedTech Code. The general part of the NSR survey included data on the country and the NS for both surveys (Question 1 or Q1). The other part included questions (Q1-Q12) related to: financial resources for educational events that are available to the NS or IM; selection criteria for financing of educational events 
Table 1: Survey results for EFLM national representatives.

\begin{tabular}{lr}
\hline National representatives $(\mathbf{n}=\mathbf{2 5})$ & \\
\hline Q1: Will selection criteria for financial support of society-members \\
change in the future?, \% & 16 \\
No, they will remain the same & 28 \\
Yes, they will change slightly & 24 \\
Yes, they will change significantly & 32 \\
Do not know
\end{tabular}

Q2: In your opinion, which selection criteria will be adopted in the future?a $\%$

The institutional director will make the decision,

without specific criteria

The laboratory chief was will make the decision,

without specific criteria

The laboratory chief will make the decision,

supporting at least a poster presentation

The institutional director/laboratory chief will make

the decision by defined selection criteria

NS grants

According to IVD representative suggestions

Q3: When does your NS usually organise national congresses?, \% In tourist seasons

Out of tourist seasons

Both

Q4: Does your NS provide educational grants for participation in international congresses and conferences?, \%

Yes

No

Q5: How many educational grants does your national society provide yearly?, \%
$1-5$
6-10
$11-20$
$>20$

Q6: Which are the selection criteria adopted by your NS?, \% Scientific and professional bibliography of the member

Objective evaluation of abstracts according to

previously defined criteria

Age limit (for younger members)

Q7: Do IVD industry representatives support educational

scholarships for HCPs in agreement with your national society?, \% Yes

No

Q8: Do IVD industry representatives support financially (for travel, accommodation) the lecturers on your NS congresses?, \% Yes

No

Q9: How do IVD industry representatives support financially the grants and scholarships for your NS members?, \%

In response to a written request submitted by the NS

or healthcare organisation

Through foundations established by the NS

Through foundations established IVD industry companies
Table 1 (continued)

\begin{tabular}{lr}
\hline National representatives $(\mathrm{n}=\mathbf{2 5})$ & 8 \\
\hline Through foundations established by healthcare & \\
organisation & 52 \\
There are no grants provided by the IVD industry & 4 \\
Other &
\end{tabular}

Q10: Are IVD industry representatives involved in decision about selection criteria of HCPs for financial support of third party organised conferences?, \%

Yes, they define selection criteria and make the final decision without the cooperation of the NS

Yes, they define selection criteria and make the final

decision with the cooperation of the NS

No, they are not involved at all

Q11: Did you implement the new MedTech Europe Code into your NS ethical code?, \%

Yes, we did it

Yes, but we are still working on updates $\quad 20$

No, we did not, but will do so in the future 52

No, we did not and will not do it in the future 12

Q12: Is your NS EB working on the common strategy for implementation of MedTech Europe Code in cooperation with IVD industry representatives?, \%

Yes, we have already defined some rules related to 12

MedTech Europe Code

Yes, we had some meetings just to discuss about it 28 No, but we have planned to do it in the future 28 No, we will do it, but we have not planned it yet $\quad 28$ No, we will not do it

EFLM, European Federation of Clinical Chemistry and Laboratory Medicine; HCPs, health care professionals; IVD, in vitro diagnostics; NS, national society. ${ }^{a}$ Multiple answers allowed.

in current practice and for the future; knowledge and practice about the requirements of the location and season of national educational events; questions about adoption and selection criteria for education grants given by the NS; questions about the implementation of MedTech Europe into the NS's Ethical Code, as well as the implementation of MedTech Europe in the practice (Table 1).

The survey for IMs in the general part included data on country, NS and age of the participant. The other part included questions about employment, availability of financial resources for educational events, selection criteria for financing of educational events, the IM's point of view about being directly financed by the IVD industry, number of congresses and participation modalities in last 5 years, and their opinion about the location and the venue of national congresses (Tables 2 and 3 ).

In order to collect information on previous and current practice and future steps for incorporation of the MedTech Code, two surveys were conducted using LimeSurvey, (Version 2.67.1+ 170626, LimeSurvey $\mathrm{GmbH} /$ Germany). The survey for NSRs was sent through the mailing lists of all 40 national societies, who are members of the EFLM. pate in the EFLM WG-CPE survey for IMs. The announcements were sent by the EFLM office and NSRs, who were asked to encourage their 
Table 2: Survey results for EFLM IMs (part I).

\begin{tabular}{lr}
\hline IMs $(\mathrm{n}=\mathbf{3 2 2})$ & \\
\hline Age, years & \\
$\mathbf{3 0}$ & $\mathbf{1 8}$ \\
$\mathbf{3 1 - 4 0}$ & $\mathbf{7 0}$ \\
$>\mathbf{4 0}$ & \\
Q1: Employment, \% & 40.7 \\
(a) University hospital laboratory & 28.9 \\
(b) General hospital laboratory & 5.9 \\
(c) Private hospital-clinic laboratory & 2.5 \\
(d) Public outpatient clinic laboratory & 5.9 \\
(e) Private outpatient clinic laboratory & 4.6 \\
(f) University faculty & 6.5 \\
(g) Combination of clinic and faculty & 5.0 \\
(h) Other (retired, freelance) &
\end{tabular}

Q2: Have you ever been directly financially supported by the IVD industry for the third party events/conferences?, \%

(a) Yes, always when I attend third party organised events $\quad 19.6$

(b) Yes, but just for some events in my career

(c) Yes, but in the past

(d) No, I have never received financial support by an IVD industry directly

Q3: How many congresses and conferences did you attend in the last 5 years?, \%
(a) $1-3$
(b) $4-5$
(c) 6-8
(d) $9-10$
(e) more than 10
(f) do not remember

Q4: Does your NS provide educational grants for attending congresses and conferences?, \%
(a) Yes
(b) No
(c) Do not know

Q5: How many educational grants have you gained from your NS in the last 5 years?, \%
(a) 1-3
(b) 4-5
(c) More than 5
(d) None

EFLM, European Federation of Clinical Chemistry and Laboratory Medicine; IM, individual member; IVD, in vitro diagnostics. Bold values indicate number of participants.

members using NS newsletters. The invited HCPs and/or APs were kindly asked to provide some basic information about their experience and opinions regarding the future practice of the IVD industry providing financial support for educational events.

The first announcement and invitation to participate in both surveys was made at the beginning of November 2017, with a deadline of the 15th of December. For better feedback the invitation was repeated and a second round for both surveys was made between 15th of December 2017 and 28th of February 2018. The whole process was repeated once more but separately; the third round for the NSR survey was between 1st April and 1st May 2018, and for IMs from 5th May through 14th June 2018.

\section{Statistics}

A descriptive statistical analysis of the results was carried out. Data were evaluated using statistical software STATISTICA 13 (StatSoft TIBCO Softwarwe Inc., Tulsa, OK, USA).

\section{Results}

Out of the 40 EFLM NSs, 25 replied to the survey: Albania, Belgium, Croatia, Czech Republic, Denmark, Estonia, Greece, Hungary, Ireland, Israel, Italy, Kosovo, Lithuania, Macedonia, Montenegro, Norway, Poland, Portugal, Russia, Serbia, Slovakia, Slovenia, Spain, Ukraine and the UK.

More than half of NSRs declared that many different types of financial resources were available for supporting the continuous professional education of HCPs (Figure 1); in most cases (44\%) NSs provide one to five events annually (Table 1). It was shown that the selection criteria in most countries depend on the decisions of the laboratory chief or the institutional director, without any specific criteria $(76 \%)$ or with the criterion of supporting at least those who have a poster presentation ( $80 \%$, Figures $2,3 \mathrm{~A}$ and $B)$. In this regard, most NSRs commented that this will be the most probable criterion to be adopted in the future. The frequency of use of each funding resource by NSRs and IMs is summarised in Figure 4A and B, respectively. In $72 \%$ of the cases IVD industry representatives were not involved in decisions about the selection criteria of HCPs for financial support of third-party organised conferences, and in $68 \%$ of the cases they did not support educational scholarships. NSs also answered that there were not a lot of changes related to selection criteria, but it was noticed that in most cases $(80 \%)$ IVD industry-representatives were not able to choose the candidate for financial support. Most of the national congresses were organised in the place of residence of the majority of the invited participants, but there were still some of them organising events in a holiday location with a highly developed tourism aimed at congresses. Nevertheless, 80\% answered that the events were organised out of the tourist season. Most of the participants have implemented the MedTech Code into their NS's ethical code or they are working on updates or plan to implement it in the near future. Three NSRs declared that they will not implement it at all.

Answers of the IM survey were submitted from 322 participants, from 31 EFLM NSs. The results are presented in Tables 2 and 3. The most frequent were answers from Croatia (45), the UK (42), Italy (37), while less or equal to 10 answers were received from Macedonia (10), Greece (7), 
Table 3: Survey results for EFLM individual members (part II).

\section{Individual members $(\mathrm{n}=322)$}

Q6. What is your opinion about direct financial support by IVDs?, \%

It is necessary for IVD product promotion

It is totally unacceptable

\begin{tabular}{rrrr} 
Disagree & Partially agree & Agree & Do not know \\
\hline 22.7 & 36.3 & 31.1 & 9.9 \\
29.8 & 36.3 & 20.5 & 13.4 \\
49.7 & 18.7 & 15.8 & 15.8
\end{tabular}

Q7. In the last 5 years, how frequently did it happen to you to attend congress and conferences as..., \%

A first author of poster presentation

\begin{tabular}{rrrrrr} 
Never & Rarely & $\begin{array}{r}\text { In about half } \\
\text { of the cases }\end{array}$ & Mostly & Always & $\begin{array}{r}\text { Don't } \\
\text { remember }\end{array}$ \\
\hline 39.5 & 24.8 & 16.1 & 12.4 & 3.1 & 4.1 \\
25.8 & 22.4 & 14.0 & 23.0 & 11.5 & 3.3 \\
45.3 & 22.4 & 10.5 & 12.1 & 2.2 & 7.5 \\
30.7 & 29.8 & 14.9 & 14.6 & 4.7 & 5.3 \\
21.7 & 32.2 & 10.9 & 18.0 & 13.4 & 3.7
\end{tabular}

Q8. How frequently does your national society provide educational grants for attending congresses and conferences?, \%

A co-author of poster presentation

Just passively, as a participant

\begin{tabular}{rrrrrr} 
Never & Rarely & $\begin{array}{r}\text { In about half } \\
\text { of the cases }\end{array}$ & Mostly & Always & $\begin{array}{r}\text { Don't } \\
\text { know }\end{array}$ \\
\hline 1.9 & 11.8 & 6.5 & 12.4 & 14.6 & 52.8 \\
4.3 & 19.0 & 4.3 & 6.8 & 7.8 & 57.8 \\
\hline
\end{tabular}

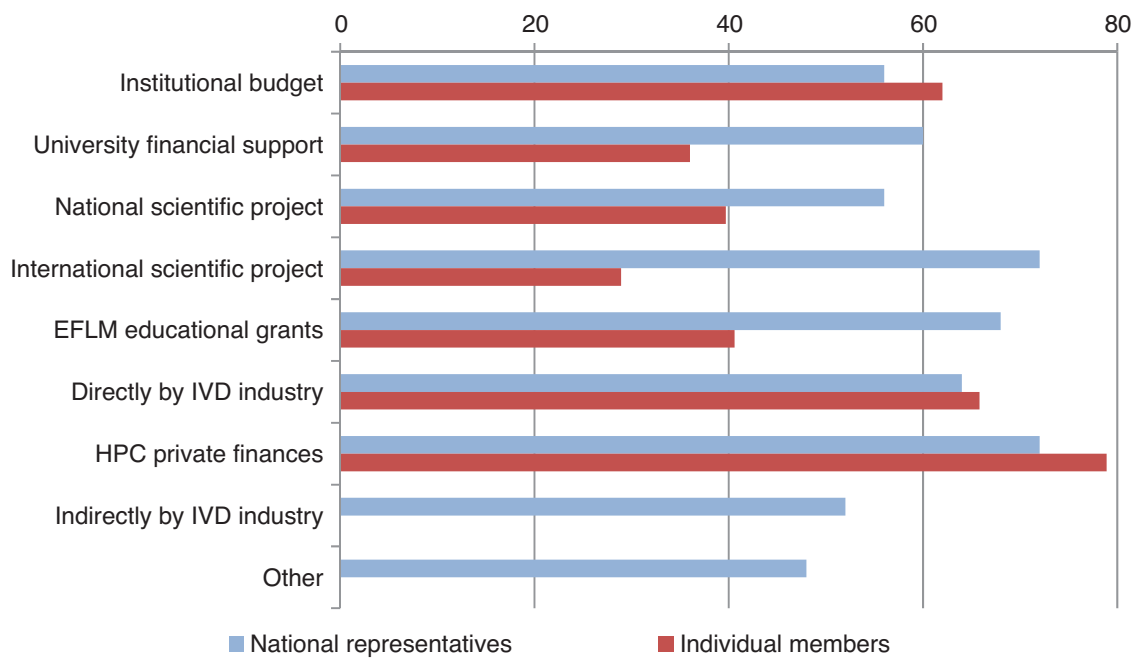

Figure 1: Which financial resources are available in your country to support continuous professional education of HCPs? (multiple answers allowed).

Switzerland (7), Estonia (6), Finland (6), Germany, (5), Portugal (5), Russia (5), Bulgaria (4), Netherlands (4), Bosnia and Herzegovina (3), Czech Republic (2), Ireland (2) and Kosovo (2). Only one answer was received from Albania, Austria, France, Hungary, Iceland, Montenegro, Slovakia and Ukraine. Most of the participants work in a university hospital $(40.7 \%)$ or general hospital laboratory (28.9\%). Again, most respondents stated that their NS provides educational grants for attending congresses and conferences (58.1\%). It was also shown that there was a significant number of individuals (71.2\%) who used direct financing from the IVD industry, mostly in the past and just for a few educational events. Moreover, 68 individuals $(19.6 \%)$ declared that they always use direct IVD industry financing.

Regarding the selection criteria for educational events, IMs answered that their institutional director $(50.3 \%)$ or laboratory chief $(70.1 \%)$ generally made the 


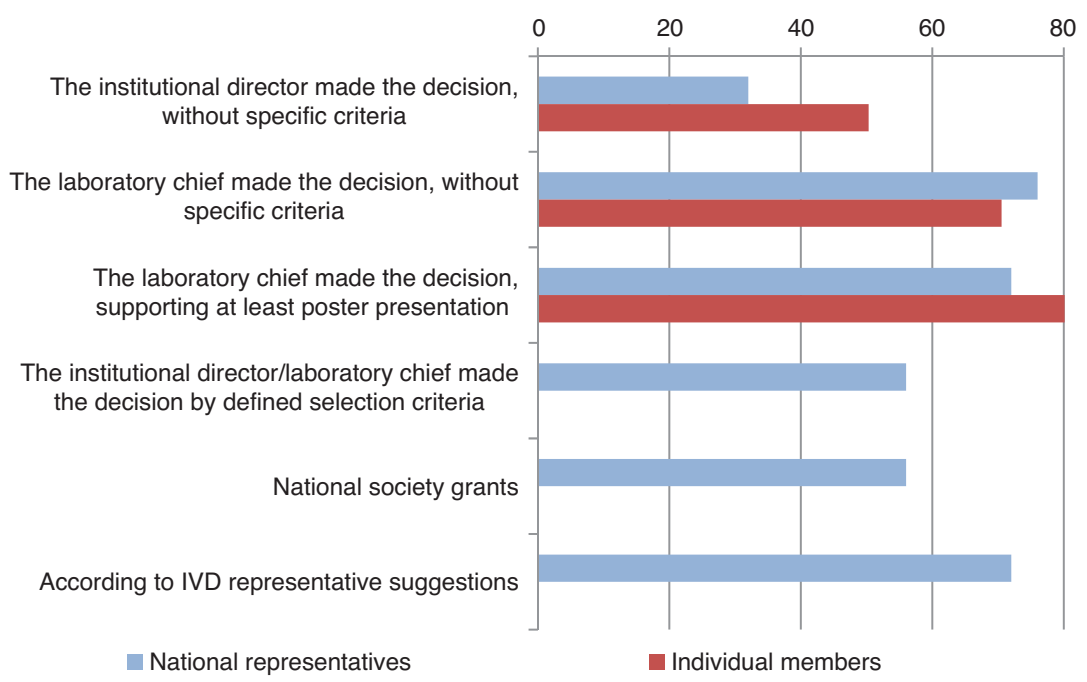

Figure 2: When your society members were financially supported by IVD industry representatives for third party organised conferences, which selection criteria were adopted in the past? (multiple answers allowed).

decision, without specific criteria, but the majority of answers were graded as happening rarely or in the half of the cases. Some respondents expressed their point of view about being directly financed by the IVD industry: $31.1 \%$ totally agreed and $36.3 \%$ partially agreed that direct financing of customers by the IVD industry is reasonable. Furthermore, 36.3\% partially agreed, and 20.5\% totally agreed that direct financing of HCPs by the IVD industry is necessary for the promotion of IVDs. Approximately half of the IMs believed that direct financial support is unacceptable (Table 3). Some respondents commented on congress locations and the venue of national congresses (Figure 5A and B). Almost half of the study participants stated that the event location and venue should be in or near a city or town, which is a recognised scientific or business centre, while the remaining half preferred tourist locations.

\section{Discussion}

Our survey showed that a consistent part of the NSs or the IMs use direct or indirect funds from the IVD industry for the organisation of or participation at educational events; only $9 \%$ of the IMs enrolled declared that they have never received any financial support from the IVD industry. This confirms the increasing medical industry presence in the professional life and evolution of modern HCPs, which led to the need for regulations and the creation of the MedTech Europe Code. Some of the NSs which answered the questionnaire have already implemented the Code or are intending to do so in the near future. Others have not yet adopted it, and three out of the 25 NSRs declared that their society is not intending to introduce the Code in their daily practice. This reveals heterogeneity in the perception of the MedTech role among NSs, as well as the need to understand the reasons for such heterogeneity and the strategies for reducing it.

This may depend on some criticisms raised about the implementation methodology and the content of the Code raised by HCPs in other fields of medicine [7]. Furthermore, it may create some pressure on organisers of scientific meetings regarding the sustainability of the events, leading them to find new funding sources or to increase registration fees, the number of delegates and academic funding, at the same time reducing the expenditures for leisure, refreshment and other activities. These aspects, along with difficulties of dealing with new regulations and bureaucracy, may be the cause of the incomplete acceptance of the code by NSs.

Decisions about IVD industry-financed attendance of third-party scientific events were in most cases taken by the laboratory head/director without any specific criteria or at least with the criterion to support those who have a poster presentation. This may raise some concerns about the equity of the distribution of IVD industry funding among the professionals of each laboratory, which is left to the discretion of the director (who probably also decides about poster presentations). IVD industry companies seem to variably influence the choice of the HCPs to support a conference (five NSRs said mostly or always while seven NSTs declared just in half of the cases); nevertheless, often the IVD industry was not able to identify which candidate to support. This means that communication between the 
A

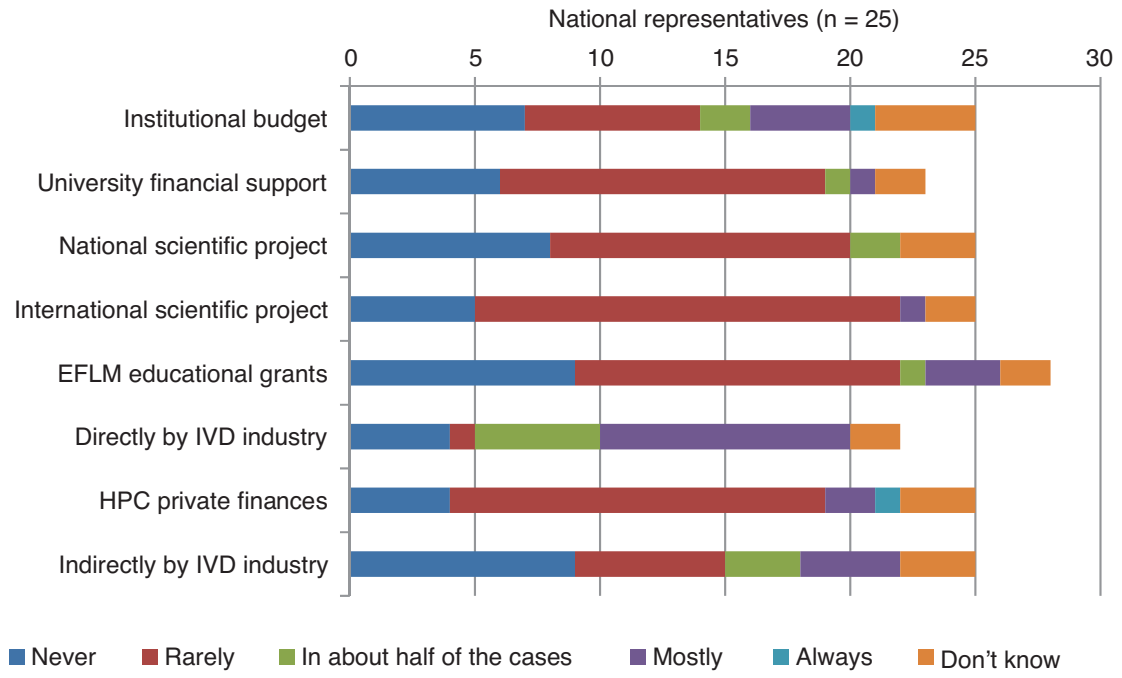

B Individual members $(\% ; n=325)$

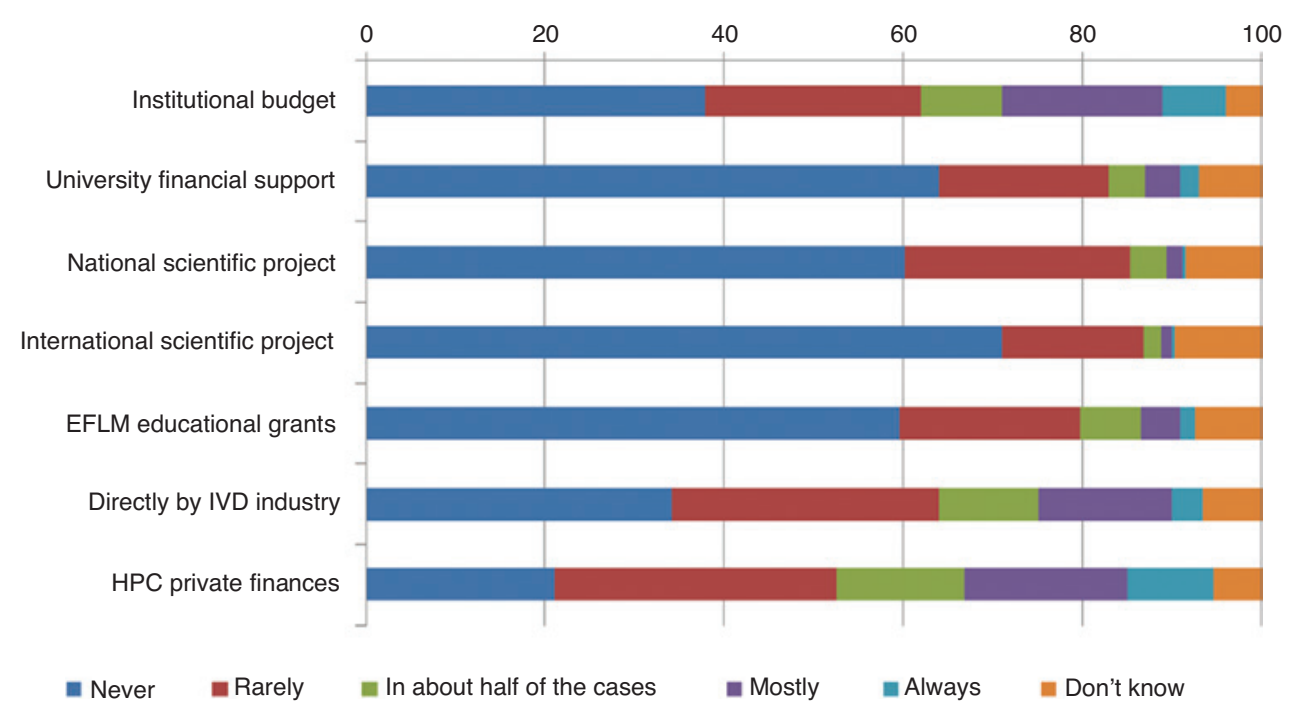

Figure 3: How frequently your society members used the financial resources you said are available to support continuous professional education of HCPs? (A) National representatives, (B) IMs. (multiple answers allowed).

laboratory head/director, laboratory staff and the IVD industry needs to be enhanced in order to improve the modalities and equity of financial support.

A specific aspect regarding the organisation of scientific events was investigated in the survey: i.e. the choice of the location. Most of the events currently take place outside the tourist season in locations at or near the organising institution or at least at the place with the greater number of participants. Nevertheless, most of the IMs prefer the scientific events to be performed in highly touristic locations. This underlines the need of HCPs to combine education with recreational activities and should be kept in mind by the societies and IVD industry companies when organising scientific events. Nevertheless, as stated by the Code, the entertainment aspect should not be the main attraction of the educational event, and venues such as leisure resorts and spas need to be considered with caution because these should not become the major factor in the choice of the venue. However, some, especially small countries have to deal with a limited number of places and enough big halls for organising their national or international events/ congress, which are usually placed within hotels in the tourist centres [1].

What is interesting is that we have found several significant differences between NSRs' and IMs' responses. 
A

National representatives $(n=25)$

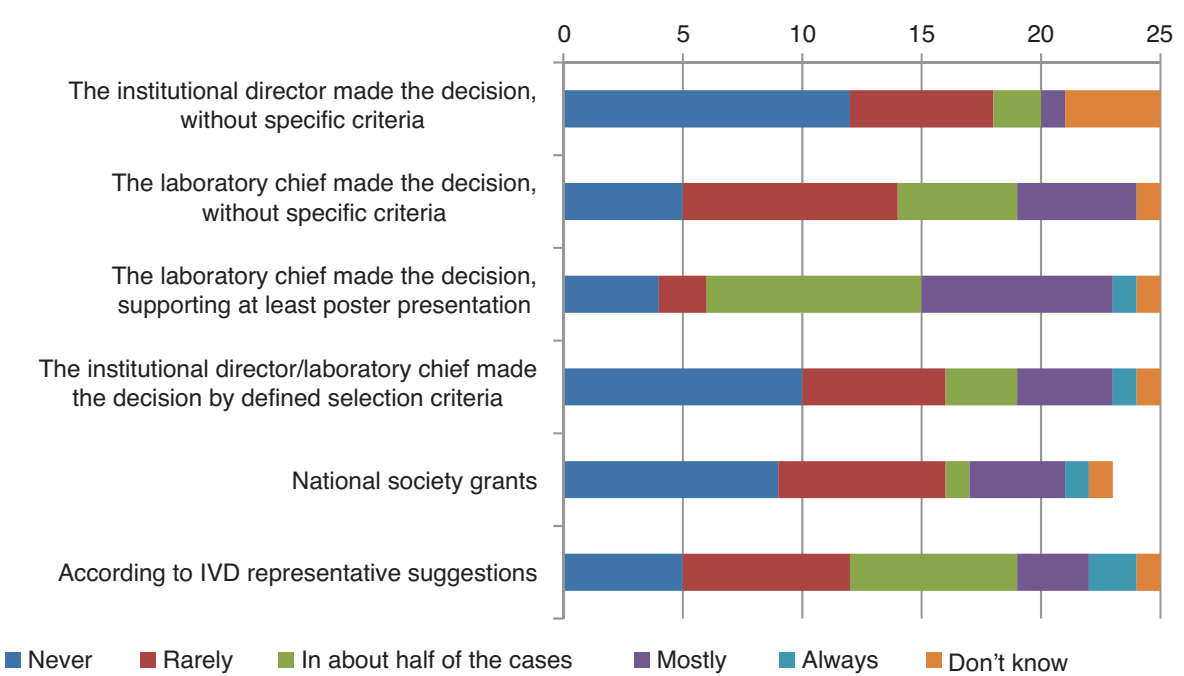

B

Individual members $(\% ; \mathrm{n}=322)$

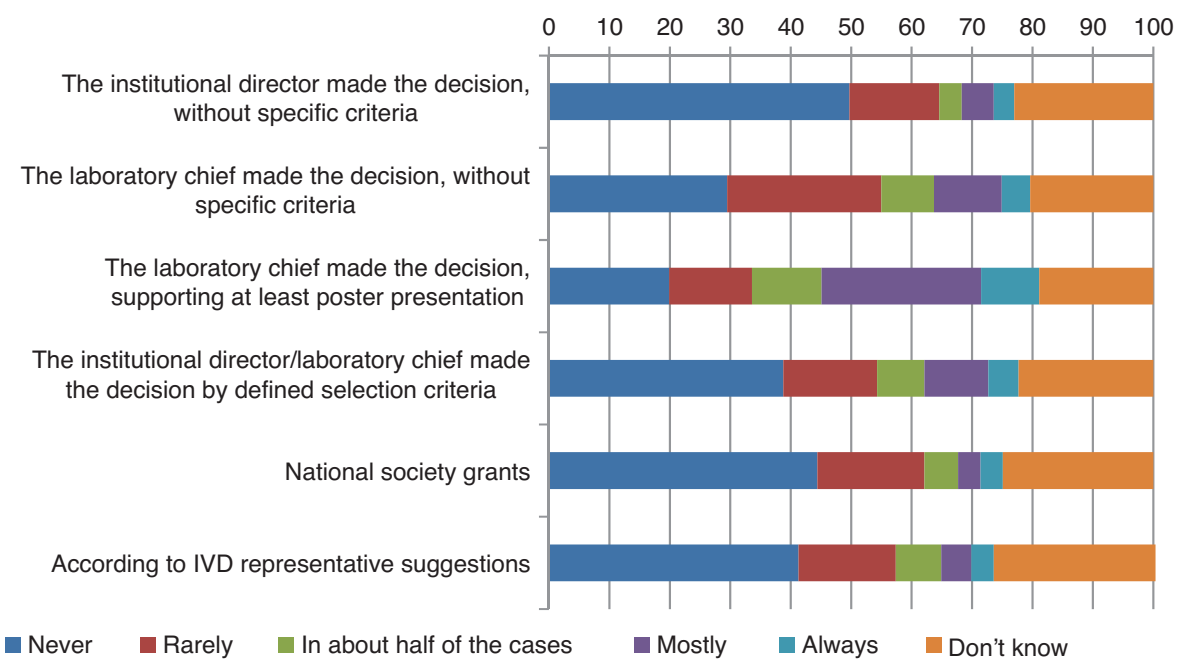

Figure 4: How frequently each selection criteria was adopted in the past? (A) National representatives, (B) IMs. (multiple answers allowed).

In reference to the question about frequency of use of financial sources available for scientific society members (Figure $3 \mathrm{~A}$ and B), $\geq 60 \%$ of the IMs stated that they had never used support from a university, national and international scientific projects and EFLM educational grants, while NSRs declared that only $20 \%-32 \%$ of members had never used these forms of support. IMs replied that the most used sources of finance were their own private funds (18.3\%), their institutional budget (18\%) and direct support from the IVD industry (14.9\%), whereas NSRs declared that the most common support is obtained from the IVD industry (40\%). Moreover, 44\% of NSRs stated that their NS provides at least one to five educational grants per year, as well as more than $20 \%$ who replied that IVD industry representatives financially support the grants and scholarships for NS members (Table 1). However, only $58 \%$ of IMs knew about educational grants provided by NSs and 33.6\% declared that they have not obtained any educational grant in last 5 years (Table 2). These results show that only a small number of members are familiar with the financing of participation in scientific events by NSs and that is why both IMs and NSRs point to direct financing by IVD industry companies as one of their main financial sources. Close cooperation between the NSs and IVD industry representatives on the implementation of the Mech-Tech Code is very important in this context. 
A

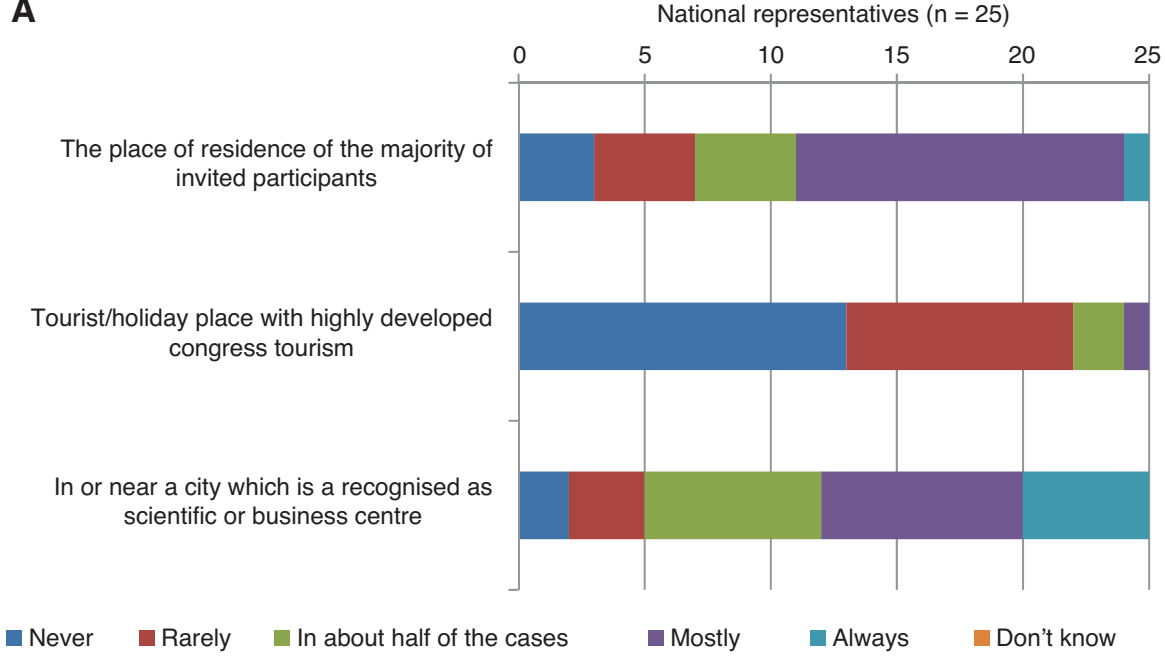

B

Individual members $(\% ; \mathrm{n}=322)$

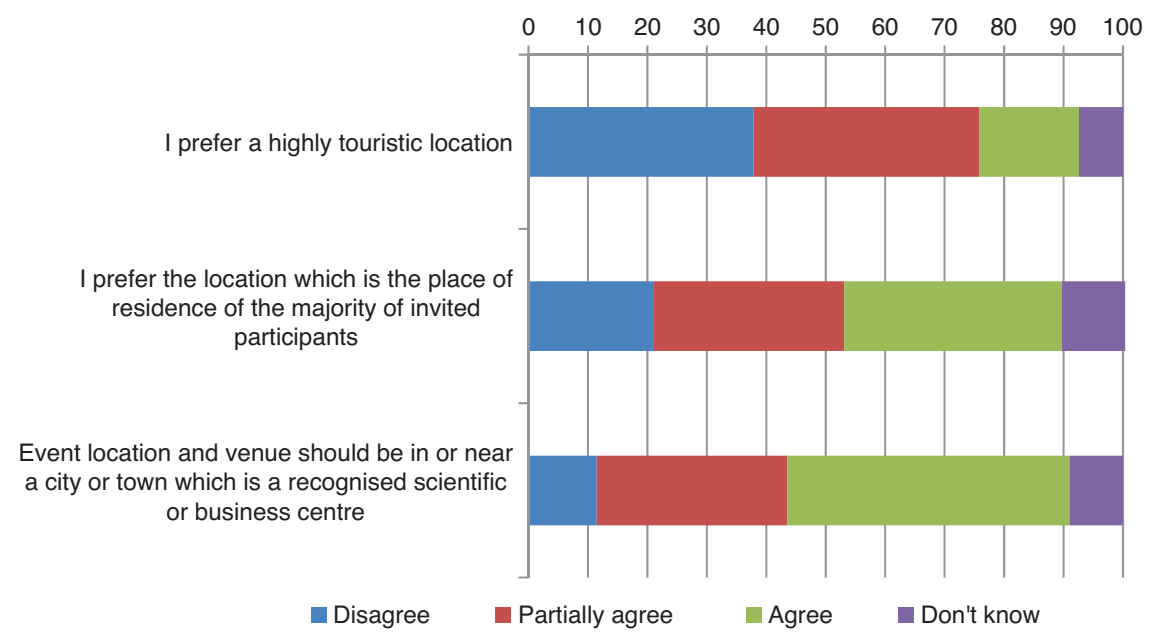

Figure 5: Location and venue of scientific events - answers from national representatives (A) and IMs opinions (B).

\section{Limitations}

This study has some limitations, mainly correlated with the common limitations of a survey and the small number of NSRs and especially IMs who answered the questionnaire. On the other hand, this is the first attempt to investigate the landscape of MedTech acceptance and implantation among EFLM NSs, showing some interesting aspects and issues which need to be improved.

\section{Conclusions}

In conclusion, when these surveys were carried out, the MedTech Europe code had already been adopted or was about to be adopted in numerous EFLM NSs, but most of them have not implemented it as yet. The use of the Code and better communication between IVD industry representatives and HCPs are necessary to guarantee an improved and fair use of financial support, as well as better choices for the organisation and attendance at scientific events.

Acknowledgments: We would like to thank Panagiotis Paliogiannis, MD, PhD, from the Department of Biomedical Sciences, University of Sassari, Sassari, Italy, who helped in writing the manuscript.

Author contributions: All the authors have accepted responsibility for the entire content of this submitted manuscript and approved submission. 
Research funding: None declared.

Employment or leadership: None declared.

Honorarium: None declared.

Competing interests: The funding organisation(s) played no role in the study design; in the collection, analysis, and interpretation of data; in the writing of the report; or in the decision to submit the report for publication.

\section{References}

1. Pillay TS. The new MedTech Europe directive: implications for educational activities in pathology and laboratory medicine. J Clin Pathol 2017;70:185-6.
2. MedTech Europe. https://www.medtecheurope.org/resourcelibrary/medtech-europe-code-of-ethical-business-practice/. Accessed: 6 Feb 2019.

3. AdvaMed. AdvaMed Educational Conference support brochure. http://www.advamed.org/sites/default/files/resource/ advamed_educational_conference_support_brochure.pdf. Accessed: 6 Feb 2019.

4. MedTech Europe. The MedTech Europe Code of Ethical Business Practice. http://www.medtecheurope.org/sites/default/ files/resource_items/files/20151202_MedTechEuropeCode.pdf. Accessed: 6 Feb 2019.

5. Arie S. The device industry and payments to doctors. Br Med J 2015;351:h6182.

6. MedTech Europe. https://www.ethicalmedtech.eu/conferencevetting-system/objective. Accessed: 6 Feb 2019.

7. Howard AJ. New Medtech code of ethics and cardiology. Eur Heart J 2018;39:3270-1. 